\title{
ESTADIAMENTO DOS CÃES COM DOENÇA RENAL CRÔNICA ATENDIDOS EM UM HOSPITAL VETERINÁRIO NO ANO DE 2013
}

Recebido: 08/08/2016

GALVÃO, André Luiz Baptista ${ }^{1}$; CARVALHO, Marileda Bonafim ${ }^{2}$.

Aceito: 02/09/2017

\footnotetext{
${ }^{1}$ Professor, Doutor, Setor de Clínica Médica de Pequenos Animais, Centro Universitário de Rio Preto/UNIRP; ${ }^{2}$ Professora Assistente, Doutora, Departamento de Clínica e Cirurgia Veterinária, Faculdade de Ciências Agrárias e Veterinárias "Universidade Estadual Paulista"/FCAV-UNESP.
}

\section{RESUMO}

A International Renal Interst Socity (IRIS) desenvolveu uma classificação para doença renal crônica (DRC) em cães. Pacientes com enfermidades que predispõem a DRC, sem alterações clínicas e laboratoriais, são considerados no estádio 0 . No estádio 1 , a creatinina sérica está inferior a $1,4 \mathrm{mg} / \mathrm{dL}$, a poliúria e polidipsia podem estar presentes, bem como a incapacidade de concentrar urina. A creatinina sérica entre 1,4 mg/dL e 2,0 $\mathrm{mg} / \mathrm{dL}$, com manifestação clínica de poliúria e polidipsia, são características dos pacientes no estádio 2 . No estádio 3 , a creatinina sérica se comporta entre $2,1 \mathrm{mg} / \mathrm{dL}$ a $5,0 \mathrm{mg} / \mathrm{dL}$, com manifestações clínicas moderadas da síndrome urêmica. No estádio 4 , a creatinina sérica está superior a $5,0 \mathrm{mg} / \mathrm{dL}$, com manifestações clínicas graves da síndrome urêmica. Objetivou-se com este trabalho estabelecer o estadiamento da DRC em cães clinicamente estáveis atendidos no Serviço de Nefrologia e Urologia do Hospital Veterinário "Governador Laudo Natel", referente ao ano de 2013, seguindo critérios de classificação da IRIS. Dos 62 cães estudados, foram identificados 17 (27\%) sadios e 45 (73\%) com DRC, destes 45, foram identificados 12 (27\%) em estádio 1, 10 (22\%) em estádio 2, 13 (29\%) em estádio 3, e 10 (22\%) cães em estádio 4. Concluímos que a DRC em cães não apresenta predileção racial e/ou sexual, sendo os cães com idade superior a 7 anos os mais cometidos. A hipertensão arterial sistêmica e a proteinúria podem estar presentes em qualquer estádio da doença.

Palavras-chave: Azotemia. Creatinina. Hipertensão. Proteinúria. 


\section{INTRODUÇÃO}

Lesões estruturais irreversíveis no parênquima renal podem evoluir progressivamente para uremia, doença renal crônica (DRC) e falência renal (POLZIN et al., 2005). Mudanças estruturais e funcionais adaptativas dos néfrons remanescentes, ocorrem na tentativa de manter a homeostase, principalmente quanto à regulação do volume e da composição do líquido corporal extracelular. Eventualmente, essas mudanças adaptativas tornam-se excessivas ou maléficas, favorecendo, ainda mais, o desenvolvimento de dano dos néfrons, instalando a DRC (CHEW et al., 2011; MALAGUTTI; FERRAZ 2011). Em pequenos animais, a DRC é caracterizada quando ocorre a redução da taxa de filtração glomerular (TFG) superior a 50\%, que persista por mais de 2 a 3 meses (CORTADELLAS, 2012).

Diante da importância da DRC na clínica de pequenos animais, a International Renal Interest Society (IRIS) desenvolveu uma classificação em estádios. O estadiamento foi realizado para facilitar o diagnóstico precoce, bem como orientar as opções em intervenção terapêutica em cada estágio, melhorando a qualidade de vida do paciente, na tentativa de retardar a evolução da doença (IRIS, 2013).

A classificação dos estádios estabelecida pela IRIS, baseia-se nas concentrações séricas de creatinina, pois permite estimar a TFG (IRIS, 2013). Para manter valores fidedignos da creatinina sérica, o paciente deve estar em jejum e hidratado, a coleta da amostra sérica deve ser realizada em até três ocasiões diferentes, no intervalo mínimo de quinze dias (POLZIN et al., 2005). Adicionalmente, devem-se excluir variações de creatinina pré e pósrenal, mesmo que já com diagnóstico de DRC (POLZIN et al., 2005).

O sistema de classificação da IRIS compreende cinco estádios. São considerados pacientes no estádio 0 , aqueles que possuem fatores ou condições que facilitam a instalação da DRC. Os pacientes no estádio 1 não apresentam manifestações clínicas evidentes, exceto a poliúria e polidipsia, a diminuição da densidade urinária pode estar presente ou não neste estádio, entretanto, a proteinúria pode ser o único achado de dano renal presente. Adicionalmente no estádio 1, a azotemia não está presente e a creatinina sérica apresentase inferior a 1,4 mg/dL. Alterações nos exames de imagens e/ou na biópsia renal podem ser também evidenciadas indicando comprometimento do órgão, classificando o paciente no 
estádio 1. No estádio 2, o paciente apresenta discreta azotemia, com a creatinina sérica entre $1,4 \mathrm{mg} / \mathrm{dL}$ e $2,0 \mathrm{mg} / \mathrm{dL}$, sem manifestações clínicas exceto poliúria e polidipsia. No estádio 3 observa-se azotemia moderada nos pacientes, a creatinina sérica varia de 2,1 $\mathrm{mg} / \mathrm{dL}$ a 5,0 mg/dL e as manifestações clínicas da síndrome urêmica devido à perda da função renal podem estar presentes. E por fim, o estádio 4 é caracterizado pela azotemia renal severa, os animais apresentam creatinina sérica maior que $5,0 \mathrm{mg} / \mathrm{dL}$, perda de função renal importante, podendo ser descrita como estádio de falência renal com manifestações clínicas graves (CORTADELLAS, 2012; IRIS, 2013).

Dentro dessa classificação realizada pela IRIS, foram determinados sub-estádios relacionados a proteinúria e a hipertensão arterial sistêmica (HAS). A primeira é a perda de proteína pela urina relacionado com a lesão glomerular e a HAS trata-se da elevação persistente da pressão arterial (PA). Ambas as condições interferem no prognóstico do paciente com DRC. Tanto a proteinúria quanto a HAS podem estar presentes nos estádios iniciais da doença $1 \mathrm{e}$ 2, e progredir para uma rápida perda da função renal, bem como a proteinúria e a HAS podem estar presentes nos estádios mais avançados da enfermidade (WAKI et al., 2010).

Por definição, a proteinúria patológica glomerular ocorre quando há alterações na permeabilidade do capilar glomerular fazendo com que proteínas de alto peso molecular ultrapassem a barreira de filtração. Enquanto que a tubular ocorre em decorrência de uma alteração nas células tubulares que prejudica a função de reabsorção das proteínas do filtrado glomerular de baixo ou médio peso molecular. Na proteinúria patológica intersticial, doenças inflamatórias permitem a passagem de proteínas para a urina através dos capilares peritubulares (CORTADELLAS, 2012; JERICÓ et al., 2015).

A relação proteína/creatinina urinária $(\mathrm{P} / \mathrm{C})$ permite a avaliação da proteinúria no cão. Após excluir qualquer possibilidade de proteinúria por causas extrarrenais, os cães azotêmicos que apresentarem valor de $\mathrm{P} / \mathrm{C}$ superior a 0,5 devem ser considerados proteinúricos. Cães com $\mathrm{P} / \mathrm{C}$ de 0,5 a 1,0 devem ser submetidos a monitoração para avaliar se esta proteinúria é de origem renal. Os animais com valores menores que 0,5 são classificados como ausência de proteinúria (IRIS, 2013). Para valores de $\mathrm{P} / \mathrm{C}$ superiores a 2,0, mesmo no estádio 1 , é indicada a intervenção terapêutica (WAKI et al., 2010). 
O rim apresenta um mecanismo de autorregulação, ou seja, é capaz de regular a pressão glomerular, através de reflexos de vasodilatação e vasoconstrição, tornando-se assim, relativamente independente da PA. Em animais saudáveis, as pressões nos capilares glomerulares mantêm-se entre os $60-65 \mathrm{mmHg}$. A proteinúria e a HAS estão intimamente relacionadas, pelo aumento da pressão intraglomerular permitindo a passagem de proteínas pela barreira glomerular, resultando na proteinúria. Adicionalmente, mecanismos compensatórios são ativados, dentre eles, ocorre a ativação do sistema renina-angiotensinaaldosterona, que promove aumento da volemia e da resistência vascular periférica (IRIS, 2013).

A HAS pode ocorrer em qualquer estádio da DRC, para melhor precisão no diagnóstico do paciente com suspeita de HAS, devem-se fazer três aferições da pressão arterial sistólica (PAS) em momentos ou atendimentos diferentes, em intervalo de sete dias (WAKI et al., 2010).

A IRIS (2013) classificou cães com a DRC com valores da PAS baseado em riscos de lesão em órgãos-alvo, que são: olhos, coração, rins e encéfalo (WAKI et al., 2010). Neste sentido é de extrema importância garantir que pressão arterial permaneça em valores adequados, devido a correta perfusão sanguínea aos órgãos e tecidos vitais (WAKI et al., 2010). As consequências da HAS podem ser variadas, podendo ocorrer azotemia, proteinúria, retinopatia hipertensiva, cegueira abrupta, hipertrofia concêntrica do ventrículo esquerdo e até acidente vascular encefálico (WAKI et al., 2010). No sistema de classificação da IRIS valores de PAS de 130 a 150 mmHg os pacientes são considerados com risco mínimo; 150 a $160 \mathrm{mmHg}$ os pacientes apresentam risco baixo; risco moderado são considerados os pacientes com a PAS de 160 a 180 mmHg e quando acima de 180 mmHg são considerados pacientes de alto risco.

Considerando a elevada casuística de nefropatas na clínica de pequenos animais, principalmente da espécie canina, este trabalho objetivou estabelecer o estadiamento da DRC em cães clinicamente estáveis atendidos no Serviço de Nefrologia e Urologia de um Hospital Veterinário. 


\section{MATERIAL E MÉTODOS}

O protocolo experimental do presente trabalho foi previamente aprovado, pela Comissão de Ética no uso de Animais (CEUA) conforme processo no 013690/11.

\section{Animais}

Foram avaliados 62 cães provenientes do canil do atendimento do Serviço de Nefrologia e Urologia Veterinária de um Hospital Veterinário, atendidos durante o ano de 2013.

Para a formação dos grupos, os pacientes foram encaminhados para exames clínicos e laboratoriais, de acordo com a abordagem semiológica descrita por Carvalho (2014).

Foram adotados critérios de inclusão para compor os grupos de animais doentes, estes deveriam ser: adultos, sem restrição de sexo ou raça e apresentar sinais clínicos e laboratoriais de DRC, nos estádios 1, 2, 3 ou 4, em condição clínica estável. Além disso, optou-se em analisar alguns critérios de exclusão que compreenderam: existência de urolitíase, obstrução urinária, infecção ou neoplasia de trato urinário, crise urêmica, comorbidades, necessidade de tratamento imediato, pacientes já em tratamento farmacológico, alimentar ou de reposição e desistência antes da segunda coleta de amostras. Para compor o grupo controle, os cães deviam ser adultos sadios, sem restrição de sexo ou raça.

\section{Classificação dos grupos}

Em conformidade com a classificação proposta pela IRIS (2013) os cães com DRC foram distribuídos em quatro grupos denominados: DRC-1, DRC-2, DRC-3 e DRC-4, de acordo com o estádio da doença.

Sendo elegíveis para compor os grupos, os pacientes sadios ou com DRC, foram submetidos a duas sessões de avaliação (exame clínico de rotina e coletas de amostras de sangue e urina) com intervalo de 24 horas.

A avaliação dos animais incluiu exame físico de rotina, mensuração da PAS, urinálise, avaliação da excreção urinária de proteína e análise do perfil bioquímico sérico (ureia e creatinina). 
Para a determinação da PAS, foi utilizado o aparelho Doppler vascular ${ }^{1}$, dotado de módulo de coleta não-invasiva. Os animais foram posicionados em decúbito lateral direito e o manguito $^{2}$ foi colocado no membro torácico esquerdo, entre o olecrano e o carpo. Os manguitos utilizados apresentaram aproximadamente $40 \%$ da circunferência do local em que foram colocados no membro torácico. Foram realizadas sete determinações e os valores limítrofes superiores e inferiores descartados para a obtenção de uma média mais acurada (TILLEY, 2008).

As amostras de soro foram processadas para determinação da creatinina (método Jaffé modificado) e ureia (método enzimático). Nas amostras de urina foram dosadas creatinina (método Jaffé modificado) e proteína total (método do vermelho de pirogalol). Todas as análises bioquímicas foram feitas com os conjuntos de reagentes do o sistema Labtest $^{3}$ para diagnóstico. Para as leituras foi empregado espectrofotômetro ${ }^{4}$ semi-automático.

Para a urinálise e avaliação da proteinúria, as amostras de urina foram obtidas por meio de cateterização uretral e analisadas no máximo 30 minutos após a coleta. Para os testes químicos foram utilizadas fitas reagentes ${ }^{5}$.

A proteinúria foi avaliada por meio da determinação da razão proteína/creatinina da urina $(P / C)$, a partir dos valores de concentração de creatinina e de proteína obtidas na mesma amostra de urina.

\section{Delineamento experimental e dados estatísticos}

O experimento seguiu delineamento em blocos casualizados com distribuição dos animais de acordo com o diagnóstico. Os resultados foram submetidos por análise de variância (Oneway ANOVA) não paramétrica (Kruskal-Wallis), considerando o fator grupo, seguida de teste de Dunn de comparação múltipla das médias $(\alpha=0,05)$.

Tomando os dados de cada parâmetro em conjuntos únicos, foram testadas as correlações (Pearson) entre eles. Analisaram-se as correlações tendo como base a concentração sérica

\footnotetext{
${ }^{1}$ Doppler Vascular DV10 Pastilha Microem-Ribeirão Preto-SP.

${ }^{2}$ Manguito Neonatal dois tubos.

${ }^{3}$ LABTEST-Labtest Diagnóstica S. A., Lagoa Santa-MG.

${ }^{4}$ LABQUEST-LABTEST-Labest Diagnóstica S. A., Lagoa Santa-MG.

${ }^{5}$ COMBUR 10 Test UX ${ }^{\circ}$-Boehringer Mannhein S. A.-Buenos Aires-Argentina.
} 
de creatinina que reflete a condição clínica dos animais (de sadio até DRC-4), que foram testadas com cada um dos demais parâmetros avaliados $(\alpha=0,05)$.

A correlação foi considerada de forte intensidade entre as variáveis quando $r>0,60$, moderada intensidade quando o valor de $r$ encontrava-se entre 0,30 e 0,60 e fraca intensidade quando $r<0,30$ (DANCEY; REIDY, 2006).

As análises foram realizadas pelo programa GraphPad Prisma version 6.02 for Windows, GraphPad Software, La Jolla California USA.

\section{RESULTADOS E DISCUSSÃO}

Dos 62 cães incluídos no estudo, 18 eram sem raça definida e os demais totalizaram 15 raças distintas, o que resultou em ampla variedade de porte e peso corporal. Em relação a faixa etária, $27 \%$ eram adultos ( $\geq 4$ anos) e $73 \%$ eram idosos (idade $\geq 7$ anos). Dos 34 (55\%) cães machos, apenas um era castrado, enquanto das 28 (45\%) fêmeas incluídas no estudo, a maioria (25) era castrada. Na Tabela 1, esses dados estão apresentados de acordo com a frequência em cada um dos cinco grupos avaliados.

As causas que motivaram a avaliação inicial dos 62 cães estudados incluíram solicitação de check-up em $23 \%$ dos casos, avaliação pré-operatória de cirurgias para correção de problemas localizados e sem comprometimento sistêmico em $32 \%$ dos animais e manifestação de sinal clínico em 45\% dos casos. Foram identificados 17 (27\%) cães sadios e 45 (73\%) cães com DRC. Nestes pacientes, os sinais clínicos relatados incluíram poliúria e polidipsia, noctúria, halitose, variação do apetite, e perda de peso lenta e progressiva, que se apresentavam de forma isolada ou combinada. 
Tabela 1 - Valores de peso e idade (média \pm erro padrão) e frequência e distribuição dos dados relativos ao porte, a faixa etária, ao sexo, a condição do trato genital e a raça dos animais avaliados, que incluíram cães sadios (controle) e de cães com doença renal crônica nos estádios 1 (DRC-1), 2 (DRC-2), 3 (DRC-3) e 4 (DRC-4).

\begin{tabular}{|c|c|c|c|c|c|}
\hline \multirow[b]{2}{*}{ Características } & \multicolumn{5}{|c|}{ Grupos Avaliados } \\
\hline & Controle & DRC-1 & DRC-2 & DRC-3 & DRC-4 \\
\hline & $n=17$ & $n=12$ & $n=10$ & $n=13$ & $n=10$ \\
\hline Peso corporal (kg) & $20,90 \pm 3,09$ & $13,95 \pm 3,32$ & $15,78 \pm 3,21$ & $17,53 \pm 4,28$ & $27,38 \pm 4,25$ \\
\hline Idade (anos) & $9,0 \pm 0,86$ & $11,58 \pm 1,25$ & $10,50 \pm 1,17$ & $11,23 \pm 0,87$ & $9,90 \pm 1,01$ \\
\hline Pequenos (até 10kg) & $5(29 \%)$ & $7(58 \%)$ & $4(40 \%)$ & $7(54 \%)$ & $1(10 \%)$ \\
\hline Médios (11 a 25kg) & $6(36 \%)$ & $4(34 \%)$ & $4(40 \%)$ & $1(8 \%)$ & $3(30 \%)$ \\
\hline Grandes (26 a 45) & $5(29 \%)$ & - & $2(20 \%)$ & $5(38 \%)$ & $5(50 \%)$ \\
\hline Gigantes (>45) & $1(6 \%)$ & $1(8 \%)$ & - & - & $1(10 \%)$ \\
\hline Adultos ( $\geq 4$ anos) & $8(47 \%)$ & $3(25 \%)$ & $3(30 \%)$ & $1(8 \%)$ & $2(20 \%)$ \\
\hline Idosos ( $\geq 7$ anos) & $9(53 \%)$ & $9(75 \%)$ & $7(70 \%)$ & $12(92 \%)$ & $8(80 \%)$ \\
\hline Machos intactos & 7 (41\%) & $6(50 \%)$ & $5(50 \%)$ & $11(85 \%)$ & $4(40 \%)$ \\
\hline Machos castrados & $1(6 \%)$ & - & - & - & - \\
\hline Fêmeas intactas & - & $1(8 \%)$ & - & - & $2(20 \%)$ \\
\hline Fêmeas castradas & $9(53 \%)$ & $5(42 \%)$ & $5(50 \%)$ & $2(15 \%)$ & $4(40 \%)$ \\
\hline Sem raça definida & $6(35 \%)$ & $5(42 \%)$ & $3(30 \%)$ & - & $4(40 \%)$ \\
\hline Pinscher & - & - & $1(10 \%)$ & $2(15 \%)$ & - \\
\hline Shih-tzu & $1(6 \%)$ & - & - & $1(8 \%)$ & - \\
\hline Yorkshire Terrier & - & - & - & $1(8 \%)$ & - \\
\hline Pequinês & - & $1(8 \%)$ & - & - & - \\
\hline Poodle & $3(17 \%)$ & $3(25 \%)$ & $1(10 \%)$ & $1(8 \%)$ & $2(20 \%)$ \\
\hline Teckel & - & $2(17 \%)$ & $1(10 \%)$ & $1(8 \%)$ & - \\
\hline Boston Terrier & $1(6 \%)$ & - & - & - & - \\
\hline Cocker & - & - & $1(10 \%)$ & $2(15 \%)$ & - \\
\hline Border Collie & $1(6 \%)$ & - & - & - & - \\
\hline $\begin{array}{l}\text { American Pit Bull } \\
\text { Terrier }\end{array}$ & $1(6 \%)$ & - & $1(10 \%)$ & $2(15 \%)$ & - \\
\hline Bull Terrier & $1(6 \%)$ & - & - & - & - \\
\hline Retriever do Labrador & - & - & $2(20 \%)$ & $2(15 \%)$ & $1(10 \%)$ \\
\hline Boxer & $2(12 \%)$ & - & - & - & - \\
\hline Pastor Alemão & - & - & - & $1(8 \%)$ & $2(20 \%)$ \\
\hline Rottweiler & $1(6 \%)$ & $1(8 \%)$ & - & - & $1(10 \%)$ \\
\hline
\end{tabular}


De acordo com os resultados de exames complementares, os 45 cães com diagnóstico de DRC foram distribuídos em quatro grupos em função do estádio da doença. Seguindo os critérios da IRIS (2013), do total de 45 animais, foram identificados 12 (27\%) cães em estádio 1, 10 (22\%) cães em estádio 2, 13 (29\%) cães em estádio 3, e 10 (22\%) cães em estádio 4. No presente estudo, os 45 cães com o diagnóstico de DRC eram cães adultos (47\%) e predominantemente idosos (53\%). Segundo Hoskins (2008) a DRC é uma desordem relativamente comum em cães e gatos idosos, trata-se da incapacidade funcional progressiva dos rins, secundária a um grande número de lesões gradativas, que resulta da destruição progressiva e irreversível do parênquima renal. Segundo Polzin et al. (2005) a DRC trata-se de uma enfermidade que pode ocorrer em cães de qualquer sexo e raça, mas é de maior ocorrência em pacientes idosos, semelhante aos achados dos cães estudados no presente estudo.

Encontram-se expressos os resultados (média \pm erro padrão da média e comparação múltipla das médias) das concentrações séricas de creatinina (SCR), densidade urinária (DU), P/C e PAS na Tabela 2, que alicerçam a classificação, seguindo os critérios estabelecidos pela IRIS (2013).

Tabela 2 - Resultados (média \pm erro padrão) referentes aos parâmetros considerados como critérios para inclusão dos animais no grupo de cães sadios (controle: $n=17$ ) ou nos grupos de cães com doença renal crônica nos estádios 1 (DRC-1: $n=12$ ), 2 (DRC-2: $n=10), 3$ (DRC-3: $n=13$ ) e 4 (DRC-4: $n=10)$. Os dados foram obtidos em dois momentos (repetição) com intervalo de 24 horas.

\section{Grupos avaliados}

Variável

Controle DRC-1 DRC-2

DRC-3

DRC-4

\begin{tabular}{|c|c|c|c|c|c|}
\hline $\mathrm{SCR}(\mathrm{mg} / \mathrm{dL})$ & $1,02 \pm 0,02 c$ & $1,07 \pm 0,04 c$ & $1,81 \pm 0,03 \mathbf{b}$ & $3,40 \pm 0,15 a b$ & $6,00 \pm 0,20 a$ \\
\hline DU & $1,034 \pm 0,00 a$ & $1,023 \pm 0,00 a c$ & $1,017 \pm 0,00 b c$ & $1,013 \pm 0,00 b$ & $1,012 \pm 0,00 b$ \\
\hline $\mathrm{P} / \mathrm{C}$ & $0,13 \pm 0,01 c$ & $1,14 \pm 0,12 \mathbf{b}$ & $0,59 \pm 0,16 c$ & $1,96 \pm 0,25 a b$ & $1,53 \pm 0,25 a b$ \\
\hline PAS (mmHg) & $137,9 \pm 1,9 b$ & $181,3 \pm 6,1 a$ & $159,0 \pm 6,1 a b$ & $186,9 \pm 6,1 \mathrm{a}$ & $180,0 \pm 7,3 a$ \\
\hline
\end{tabular}

Médias, na mesma linha, seguidas de pelo menos uma letra em comum não diferem estatisticamente entre si (Teste de Dunn $\alpha=0,05$ ).

$\mathrm{SCR}=$ creatinina sérica; $\mathrm{DU}=$ densidade urinária; $\mathrm{P} / \mathrm{C}=$ razão proteína/creatinina urinária, $\mathrm{PAS}=$ Pressão arterial sistólica. 
No presente estudo as médias de SCR não diferiram significativamente entre si quando comparados os grupos controle e DRC-1, mas houve diferença significativa entre estes e os grupos DRC-2, DRC-3 e DRC-4. Também foi constatado aumento significativo progressivo das médias de SCR relacionado com os estádios da doença. O comprometimento da capacidade de concentrar a urina, estimada pela DU, foi evidenciado por diminuição gradativa das médias, que diferiram significativamente nos grupos DRC-2, DRC-3 e DRC-4 em relação a do controle (Tabela 2).

Segundo Zatz et al. (2012) a excreção urinária de creatinina deve necessariamente igualar a sua produção, sendo a TFG a via de escoamento da creatinina, desse modo com o comprometimento da função renal e da TFG, a SCR aumenta, conforme a severidade e grau de déficit renal, semelhante aos achados dos pacientes com DRC do presente estudo, e estadiado pela IRIS (2013).

Adicionalmente, azotemia se refere à retenção de resíduos nitrogenados não protéicos no sangue, são estes compostos a ureia e a creatinina, que são normalmente eliminados pelos rins (ZATZ et al., 2012). A SCR foi descrita como um indicador mais preciso da função renal quando comparada a ureia, pois ao contrário desta, não é consideravelmente influenciada por hemorragias gastrintestinais, além de não ser reabsorvida pelos túbulos (FINCO, 1995).

Em pacientes com DRC Hall (2011) descreveu que as manifestações clínicas de poliúria e polidipsia se justificam devido ao intenso fluxo de líquido tubular que ocorre na doença, resultando na incapacidade de reabsorção de água, fatores estes que impedem que o mecanismo contracorrente opere de forma efetiva, consequentemente a capacidade de concentração urinária fica comprometida, resultando em redução da DU e, clinicamente em poliúria e consequentemente polidipsia compensatória. Segundo Zatz et al. (2012) a DU é potencialmente mais sensível que a azotemia em detectar a DRC. Nos pacientes com DRC do presente estudo, foi relatado pelos proprietários a poliúria, polidipsia e noctúria, além disso, foi evidenciada diminuição da capacidade de concentração da urina estimada pela DU, sendo observada redução gradativa das médias nos grupos DRC-2, DRC-3 e DRC-4 em relação ao grupo controle, bem como foi observado a elevação gradativa das médias da SCR nos grupos DRC-2, DRC-3 e DRC-4. 
Adicionalmente, os dados relativos à $\mathrm{P} / \mathrm{C}$ do presente estudo resultaram em médias significativamente maiores que a do controle, nos grupos DRC-1, DRC-3 e DRC-4, mas não no grupo DRC-2. O mesmo quadro foi observado em relação à PAS, cuja média do grupo DRC-2 não diferiu significativamente das do controle e DRC-1, embora as médias dos grupos DRC-1, DRC-3 e DRC-4 tenham sido significativamente maiores que a do controle (Tabela 2).

Alterações glomerulares foram evidenciadas por Akamatsu (2002) através de avaliações histopatológicas realizadas por fragmentos de córtex renal obtidos por biópsia percutânea guiada por ultrassom de dez cães com DRC em estágio avançado. No referido estudo, foi notado uma maior percentagem de glomérulos alterados $(70,27 \%)$ em contraste com menor número de glomérulos no padrão de normalidade (29,73\%). De acordo com Zatz et al. (2012) a hipertensão glomerular promove uma agressão ao glomérulo ao aumentar a tensão mecânica em suas paredes, resultando em lesões de células endoteliais, estiramento de células mesangiais, lesão em podócitos, deposição mesangial de macromoléculas e passagem de ultrafiltrado para o interstício renal. Dessa forma, uma lesão na barreira glomerular pode estender-se ao interstício, resultando em atrofia tubular e facilitando a progressão da DRC (PEIXOTO et al., 2013). As condições descritas acima estão diretamente relacionadas com a progressão da DRC, bem como podem estar associadas a HAS e proteinúria, que podem se apresentar de intensidade variada no paciente com DRC, como pôde ser evidenciado no presente estudo, pois as médias significativamente maiores em relação a P/C e a PAS foram dos grupos DRC-1, DRC-3 e DRC-4 quando comparadas a do grupo controle. Diferente do observado no grupo DRC-2, diante de tais achados pode-se pressupor que provavelmente o grupo DRC-2 apresentava condição de DRC com comprometimento tubular predominante, como observado principalmente na média da DU. Segundo Cortadellas (2012) uma das formas de avaliação da função tubular é através da DU. Diante dos achados apresentados no grupo DRC-2, é descrito na literatura que a perda da capacidade de concentração da urina ocorre quando do comprometimento de mais de dois terços da massa renal funcional (HALL, 2011). Por esse motivo, deve-se considerar a possibilidade da existência de uma doença renal de origem tubular em animais que apresentem DU inferior a 1,030, persistentemente, mesmo sem demais alterações (CORTADELLAS, 2012). 
$\mathrm{Na}$ avaliação de cães com $\mathrm{DRC}$ e a presença dos valores de $\mathrm{P} / \mathrm{C}$ maior que 1,0 , foi descrito por Jacob et al. (2003) um maior risco de desenvolvimento de crise urêmica e óbito. A passagem de proteínas para o filtrado glomerular depende não apenas da integridade estrutural da barreira glomerular, mas também da pressão hidrostática local, caso haja uma hipertensão glomerular, essa passagem aumenta (FIGUEIREDO et al., 2013). Essa situação pode ocorrer em casos de HAS, se os mecanismos de autorregulação da manutenção da pressão glomerular forem superados (FIGUEIREDO et al., 2013). Quando ocorre a DRC, um grande número de néfrons está comprometido, os néfrons remanescentes terão que filtrar maior quantidade de plasma (hiperfiltração), o que aumenta a pressão intrarrenal (hipertensão glomerular). Este mecanismo ocorre na tentativa de preservar a TFG, com ação benéfica em curto prazo, entretanto, a longo prazo este mecanismo superativado acelera a progressão da DRC (FIGUEIREDO et al., 2013; ZATZ et al., 2012).

O gradual aumento da disfunção renal compromete também a capacidade funcional de sistemas orgânicos, principalmente do sistema cardiovascular (ROSS, 1992). No presente estudo, nos pacientes com DRC, a elevação das médias da PA foi constatada nos grupos DRC1, DRC-3 e DRC-4.

Adicionalmente, no presente estudo, foram avaliadas as correlações (Pearson) entre os diversos parâmetros do estudo e as concentrações séricas de creatina, que refletem diretamente na constituição dos grupos estudados. Houve correlação significativa entre os valores de SCR e os de DU, P/C, PAS (Tabela 3, Figuras 1, 2 e 3).

Tabela 3 - Resultados dos testes de correlação de Pearson entre os valores de creatinina sérica e outros parâmetros avaliados em cães sadios ( $n=17)$ e em cães com DRC em estádio 1 ( $n=12)$, estádio 2 ( $n=10)$, estádio $3(n=13)$ e estádio $4(n=19)$. As coletas de amostras foram feitas em dois momentos, com intervalo de 24 horas.

\begin{tabular}{llll}
\hline Correlações & $\begin{array}{l}\text { Coeficiente } \\
\text { de Pearson }(\mathbf{r})\end{array}$ & IC (95\%) & P \\
\hline SCR vs DU & $-0,5640$ & $-0,6734$ a $-0,4304$ & $<0,0001^{* *}$ \\
SCR vs P/C & 0,4782 & 0,3297 a 0,6037 & $<0,0001^{* *}$ \\
SCR vs PAS & 0,3565 & 0,1922 a 0,5013 & $<0,0001^{* *}$
\end{tabular}

$\mathrm{SCR}=$ creatinina sérica; $\mathrm{DU}=$ densidade urinária; $\mathrm{P} / \mathrm{C}=$ razão proteína/creatinina urinária; $\mathrm{PAS}=$ pressão arterial sistólica. 


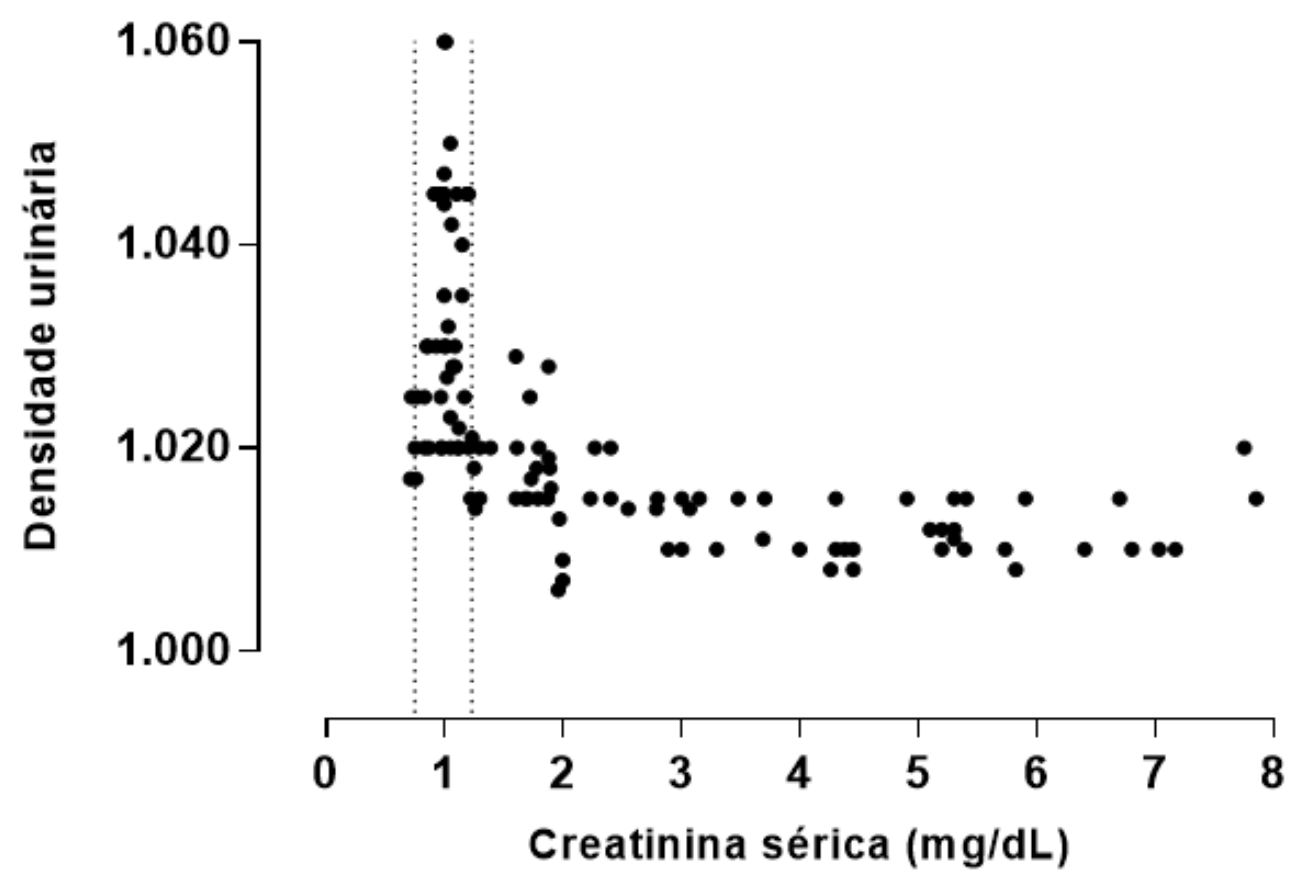

Figura 1 - Representações gráficas das correlações (Pearson) da concentração sérica de creatinina com a densidade urinária de valores obtidos em dois momentos (intervalo de 24 horas) de17 cães sadios e de cães com doença renal crônica nos estádios 1 (DRC-1: $n=12$ ), 2 (DRC-2: $n=10), 3$ (DRC-3: $n=13$ ) e 4 (DRC-4: $n=10)$. As linhas pontilhadas indicam os valores mínimo e máximo obtidos no grupo controle (cães sadios).

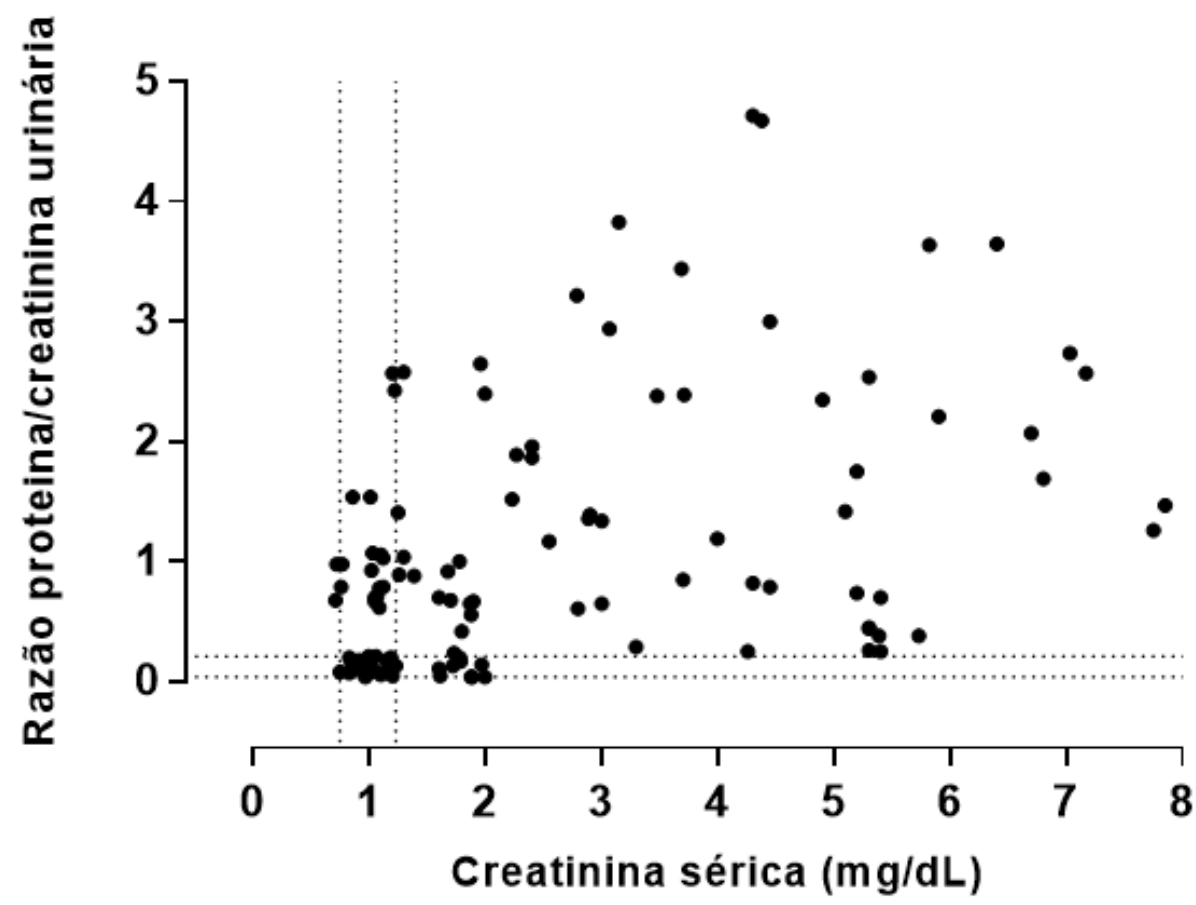

Figura 2 - Representações gráficas das correlações (Pearson) da concentração sérica de creatinina com a razão proteína/creatinina urinária de valores obtidos em dois momentos (intervalo de 24 horas) de17 cães sadios e de cães com doença renal crônica nos estádios 1 (DRC-1: $n=12$ ), 2 (DRC-2: $n=10), 3$ (DRC-3: n=13) e 4 (DRC-4: $\mathrm{n}=10$ ). As linhas pontilhadas indicam os valores mínimo e máximo obtidos no grupo controle (cães sadios). 


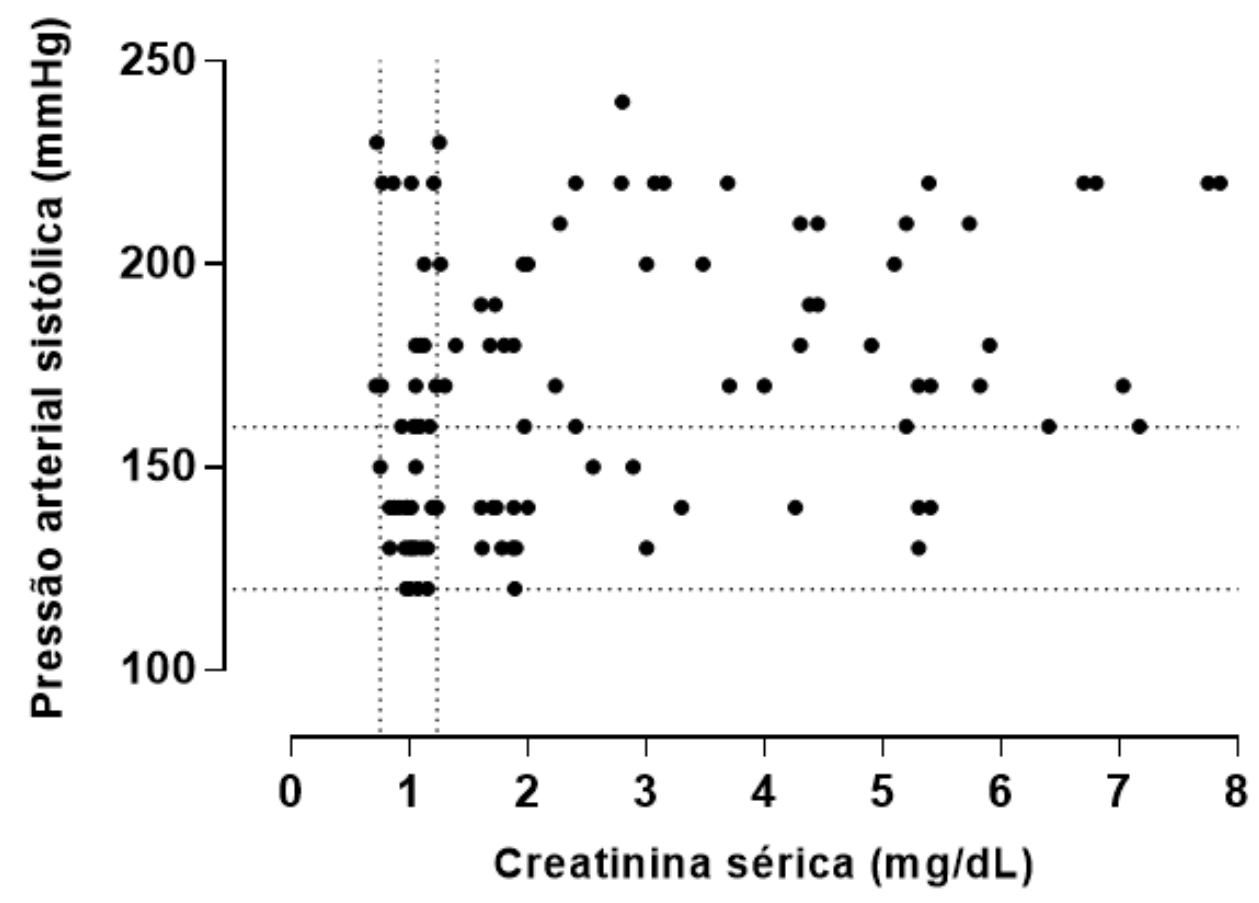

Figura 3 - Representações gráficas das correlações (Pearson) da concentração sérica de creatinina com a pressão arterial sistólica de valores obtidos em dois momentos (intervalo de 24 horas) de17 cães sadios e de cães com doença renal crônica nos estádios 1 (DRC-1: n=12), 2 (DRC-2: n=10), 3 (DRC-3: n=13) e 4 (DRC-4: $\mathrm{n}=10$ ). As linhas pontilhadas indicam os valores mínimo e máximo obtidos no grupo controle (cães sadios).

Desse modo foi evidenciada a diminuição da capacidade de concentração da urina estimada pela DU, sendo observada redução gradativa das médias nos grupos DRC-2, DRC-3 e DRC-4 em relação ao grupo controle, tal como foi notado a correlação negativa moderada entre SCR e DU ( $r=-0,5640$ e $p<0,0001)$, como supracitado na DRC a SCR aumenta, conforme a severidade e grau de déficit renal, bem como a função tubular se torna comprometida, pois o mecanismo contracorrente não mais trabalha de forma efetiva, consequentemente a capacidade de concentração urinária fica comprometida, resultando em redução da DU (HALL, 2011; ZATZ et al., 2012).

A SCR apresentou correlação positiva moderada com PAS ( $r=0,3565$ e $p<0,0001)$. Vários estudos mostraram que, durante a HAS em ratos, a angiotensina II é responsável pela instalação de processo inflamatório vascular (HARRISON, 2013). A angiotensina II na situação de HAS promove o aumento da atividade de linfócitos T e macrófagos no endotélio vascular, como também, o aumento na liberação de substâncias quimiotáxicas. Tais condições contribuem para a instalação do processo inflamatório no endotélio vascular, causando disfunção endotelial, consequente aumento da resistência vascular periférica (HARRISON, 
2013). A elevação da PA pode apressar a progressão da DRC (TOTO et al., 1995). Segundo Schiffrin et al. (2007) a HAS é identificada como um fator de risco expressivo para o desenvolvimento de falência renal. Em cães, Jacob et al. (2003) demonstraram que o diagnóstico da HAS no momento do diagnóstico inicial da DRC pode ser associado com maior risco de ocorrência de crise urêmica, piora da função renal e morte. Nesse estudo 31\% dos cães apresentaram HAS secundária a DRC e tiveram mau prognóstico.

\section{CONCLUSÃO}

Concluiu-se que a DRC é uma enfermidade de cães idosos, correspondendo no presente estudo a 53\% dos pacientes atendidos. Adicionalmente, a enfermidade não apresenta predileção racial e/ou sexual, bem como a hipertensão arterial sistêmica e a proteinúria podem estar presentes em qualquer estádio da doença.

\section{STAGING OF DOGS WITH CHRONIC RENAL DISEASE AT A VETERINARY HOSPITAL IN THE YEAR OF 2013}

\section{ABSTRACT}

T he International Renal Interest Society (IRIS) has developed a classification for chronic kidney disease (CKD) in dogs. Patients with diseases that predispose to CKD, without clinical and laboratory abnormalities, are considered at stage 0 . At stage 1 , serum creatinine is below $1.4 \mathrm{mg} / \mathrm{dL}$, polyuria and polydipsia may be present, as well as the inability to concentrate urine. Serum creatinine levels between $1.4 \mathrm{mg} / \mathrm{dL}$ and $2.0 \mathrm{mg} / \mathrm{dL}$, with clinical manifestations of polyuria and polydipsia, are characteristic of stage 2 . At stage 3 serum creatinine ranges from $2.1 \mathrm{mg} / \mathrm{dL}$ to $5,0 \mathrm{mg} / \mathrm{dL}$, with moderate clinical manifestations of uremic syndrome. At stage 4, serum creatinine is greater than $5.0 \mathrm{mg} / \mathrm{dL}$, with severe clinical manifestations of uremic syndrome. This paper aims to establish the CKD staging in clinically stable dogs attended in the Nephrology and Urology service at the "Governador Laudo Natel" Veterinarian Hospital, in the year of 2013. Concerning the 62 studied dogs, 17 were healthy (27\%) and 45 presented the CKD (73\%). Regarding the 45 dogs with CKD, 12 dogs (27\%) were identified as stage 1, 10 dogs (22\%) stage 2, 13 dogs (29\%) stage 3 , and 10 dogs (22\%) were stage 4 . In conclusion, CKD consists of an old dogs' disease (dogs over 7 years), with no breed or sexual preference. Systemic arterial hypertension and proteinuria may be present at any stage of the disease.

Keywords: Azotemia. Creatinine. Hypertension. Proteinuria. 


\section{ESTADIOS DE LA ENFERMEDAD RENAL CRÓNICA EN PERROS ATENDIDOS EL AÑO DE 2013 EN EL HOSPITAL VETERINARIO}

\section{RESUMEN}

a International Renal Interst Socity (IRIS) desarrolló una clasificación para la enfermedad renal crónica (ERC) en perros. Los pacientes con enfermedades que predisponen a la ERC, sin alteraciones clínicas y de laboratorio, se consideran en el estadio 0 . En el estadio 1, la creatinina sérica es inferior a $1,4 \mathrm{mg} / \mathrm{dL}$, la poliuria y la polidipsia pueden estar presentes, así como la incapacidad de concentrar la orina. La creatinina sérica entre $1,4 \mathrm{mg} / \mathrm{dL}$ y $2,0 \mathrm{mg} / \mathrm{dL}$, con manifestación clínica de poliuria y polidipsia, son características de los pacientes en el estadio 2 . En el estadio 3, la creatinina sérica se comporta entre $2,1 \mathrm{mg} / \mathrm{dL}$ a $5,0 \mathrm{mg} / \mathrm{dL}$, con manifestaciones clínicas moderadas del síndrome urémico. En el estadio 4, la creatinina sérica es superior a 5,0 mg/dL, con manifestaciones clínicas graves del síndrome urémico. Se pretende con este trabajo establecer la categorización de la ERC en perros clínicamente estables atendidos en el Servicio de Nefrología y Urología del Hospital Veterinario "Gobernador Laudo Natel", referente al año 2013, siguiendo criterios de clasificación de la IRIS. De los 62 perros con ERC, se identificaron 12 (27\%) perros en estadio 1, 10 (22\%) perros en estadio 2, 13 (29\%) perros en estadio 3, y 10 (22\%) perros en estadio 4. Concluimos que la ERC en perros no presenta predilección racial y/o sexual, siendo los perros con edad superior a 7 años los más afectados. La hipertensión arterial sistémica y la proteinuria pueden estar presentes en cualquier estadio de la enfermedad.

Palabras clave: Azotemia. Creatinina. Hipertensión. Proteinuria.

\section{REFERÊNCIAS}

AKAMATSU, A. Análise morfológica e funcional dos rins de cães normais e com insuficiência renal crônica. Jaboticabal: FCAV/UNESP, 2002. 51p. Dissertação (Mestrado em Medicina Veterinária), área de concentração: Clínica Médica Veterinária, Faculdade de Ciências Agrárias e Veterinárias, Universidade Estadual Paulista Júlio de Mesquita Filho, 2002.

CARVALHO, M. B. Semiologia do sistema urinário. In: FEITOSA, L. Semiologia Veterinária: A arte do Diagnóstico. 3. ed. São Paulo: Roca, 2014. Cap. 10, p. 351-366.

CORTADELLAS, O. Manual de Nefrologia e Urologia Clínica Canina e Felina. São Paulo: MedVet, 2012, 246p.

CHEW, D. J.; DIBARTOLA, S. P.; SHENCK, P. A. Canine and feline nephrology and urology. 2. ed. St. Louis: Ed. Elsevier, 2011. 534p. 
DANCEY, C.; REIDY, J. Estatística sem matemática para Psicologia: usando SPSS para Windows. Porto Alegre: Artmed, 2006. 231p.

FIGUEIREDO, V. C.; MUZZI, P. A.; SILVA, G. M.; REIS, G.; CARVALHO, L. A. R. Avaliação clínica da proteinúria em cães e gatos. Revista cães e gatos, v. 25, n. 171, p. 37-42, 2013.

FINCO, D. R. Applied physiology of the kidney. In: OSBORNE, C. A.; FINCO, D. R. Canine and Feline Nephrology and Urology. 2. ed. Philadelphia: Willians \& Willkins, 1995. Cap 16, p. 2646.

HALL, J. E. Tratado de Fisiologia Médica. 12. ed. Rio de Janeiro: Elsevier, 2011. 1151p.

HARRISON, D. G. The mosaic theory revisited: common molecular mechanisms coordinating diverse organ and cellular events in hypertension. Journal of the American Society of Hypertension, New York, v. 7, n. 1, p. 68-74, 2013.

HOSKINS, J. D. Geriatria e Gerontologia do cão e do gato. São Paulo: Roca, 2008, 437p.

IRIS. International Renal Interest Society. Staging Chronic Kidney Disease (CKD) 2013. Disponível em: <http://www.iriskidney.com/pdf/IRIS\%20A4\%20Poster.pdf >. Acesso em: 14 de janeiro de 2016.

JACOB, F.; POLZIN, D. J.; OSBORNE, C. A.; NEATON, J. D.; LEKACHAROENSUK, C.; ALLEN, T. A.; KIRK, C. A.; SWANSON, L. L. Association between initial systolic blood pressure and risk of developing a uremic crisis or of dying in dogs with chronic renal failure. Journal American Veterinary Medical Association, v. 222, p. 322-329, 2003.

JERICÓ, M.; KOGIKA, M.; ANDRADE NETO, J. P. Tratado de Medicina Interna de Cães e Gatos, Rio de Janeiro: Roca, 2015. 2394p.

MALAGUTTI, W.; FERRAZ, R. R. N. Nefrologia: uma abordagem multidisciplinar. Rio de Janeiro: Editora Rubio, 2011. 468p.

PEIXOTO, A. J.; ORIAS, M.; DESIR, G. V. Does kidney disease cause hypertesion? Current Hypertension reports, Philadelphia, v. 15, n. 2, p. 89-94, 2013.

POLZIN, D. J.; OSBORNE, C. A.; ROSS, S. Chronic renal failure. In: ETTINGER, S. J.; FELDMAN, E. C. Textbook of veterinary internal medicine. 6 ed. Philadelphia: W. B. Saunders, 2005. Cap. 260 , p. $1756-1785$.

ROSS, L. Hypertension and chronic renal failure. Seminars in Veterinary Medicine and Surgery, v. 7, p. 221-226, 1992.

SCHIFFRIN, E. L.; LIPMAN, M. L.; MANN, J. F. E. Chronic Kidney Disease. Circulation Research, v. 116, p. 85-97, 2007. 
TILLEY, L. P. Consulta veterinária em 5 minutos - espécies canina e felina. 2. ed. São Paulo: Manole, 2008. 1005p.

TOTO, R. D.; MITCHELL, H. C.; SMITH, R. C.; et al. Strict blood pressure control and progression of renal disease in hypertensive nephroesclerosis. Kidney International, v. 48, p. 851-589, 1995.

WAKI, M. F.; MORTELLI, C. R. M.; MOSKO, P. E.; et al. Classificação em estágios da doença renal crônica em cães e gatos - abordagem clínica, laboratorial e terapêutica. Ciência Rural Online, Santa Maria, 2010. Disponível em:

<http://www.scielo.br/pdf/cr/2010nahead/a741cr3532.pdf>. Acesso em: 30 de setembro de 2015.

ZATZ, R.; SEGURO, A. C.; MALNIC, G. Bases Fisiológicas da Nefrologia. São Paulo: Atheneu, 2012. P. 333-362. 